\title{
The Effect of Perfluorooctanoic Acid on the Planarian Dugesia japonica
}

\author{
Zuoqing Yuan, Jianyong Zhang*, Yanlong Zhang, Hui Zhen, Yuqian Sun \\ School of Life Sciences, Shandong University of Technology, 12 Zhangzhou Road, Zibo, PR China
}

Received: 8 July 2014

Accepted: 13 October 2014

\begin{abstract}
Perfluorooctanoic acid (PFOA) has been found to distribute and accumulate widely in the environment. In this study, the acute toxicity, behavioral activity, regeneration, antioxidant enzyme activities, and cell apoptosis effects of PFOA on planarian Dugesia japonica have been investigated. The results show that the mortality is directly proportional to the PFOA concentration, and planarian locomotor velocity (pLMV) is significantly reduced with increasing both the exposure time and PFOA concentration. The recovery of the motility for planarians pre-treated with PFOA is found to be time- and dose-dependent, and all planarians recover their motility completely after $72 \mathrm{hr}$. The appearance of auricles in regenerating animals is more easily affected by PFOA exposure in comparison to the appearance of eyespot. The SOD activities and CAT activities are changed in the PFOA-exposed planarians. Increasing PFOA exposure time or concentration can cause an obvious increase of apoptosis in the brain, eye, and parenchyma region. The results suggest that PFOA is much more toxic for inducing oxidative stress, cell apoptosis, and development toxicity in planarians.
\end{abstract}

Keywords: planarian, perfluorooctanoic acid, toxicity, regeneration, apoptosis

\section{Introduction}

The wide use of perfluorinated chemicals (PFCs) as surfactants for commercial and industrial applications over the past several decades has resulted in a broad distribution in wildlife in terrestrial and aquatic environments [1]. Perfluorooctanoic acid (PFOA), a kind of PFC, has been widely utilized in paper and food packaging, textile surface treatments, fire-fighting foams, cosmetics, lubricants, and non-stick coatings for cookware. Because of the strong carbon-fluorine bond, PFOA is stable to photolysis, hydrolysis, or biodegradation, and widespread in humans and wildlife $[2,3]$. Jin et al. [4] have surveyed many environmental samples and tap water collected from various regions of China, and reported the obvious presence of PFOA in the entire territory of China. Due to the wide distribution and bioaccumulation of PFOA in the environment, it has been proposed

*e-mail: zhangjy1977@126.com as persistent organic pollutants (POPs), and generated considerable interest to the toxicological community $[5,6]$. A number of studies have shown that PFOA has potential genotoxicity, molecular toxicity, and reproductive and developmental toxicities [7, 8]. PFOA affects the circulating sex steroid levels, and increases hepatic fatty acyl-CoA oxidase activity and oxidative damage in teleosts [9]. PFOA is able to produce oxidative stress, induce reactive oxygen species (ROS) accompanied by an increase in activities of superoxide dismutase (SOD), catalase (CAT), and glutathione reductase (GR), and also induce apoptosis with involvement of caspases in cultured tilapia hepatocytes [10]. PFOA can affect lipid metabolism in rats and cause a reduction in body weight or weight gain rate [11]. PFOA can also cause Hepatocellular adenomas, Leydig cell tumors, and pancreatic acinar cell tumors in rats $[12,13]$. Recently, Guruge et al. [7] reported that gene expression is significantly altered in the liver of rats treated with PFOA, and most of these genes are involved in the transport and 
metabolism of fatty acids and lipids, cell communication, adhesion, growth, and apoptosis. PFOA can cause hepatotoxicity in rodents, such as an increase in liver weight, incidence of hepatocellular adenoma and hypocholesterolemia, hepatocellular hypertrophy, and lipid vacuolation [14, 15].

Different from other POPs, however, PFOA is highly water-soluble, and easy to transport in an aquatic environment [16]. Despite extensive studies both on the widespread distribution of PFOAs in the environment and on the toxicology of PFOAs to mammals, little is known about its threat to aquatic ecosystems and aquatic fauna, in particular, the PFOA toxicity for freshwater invertebrates. Indeed, the eco-toxicological consequences of PFOAs in the aquatic environment are largely unknown. More information is needed for adequately assessing the impact of PFOAs on the aquatic environment. Planarians are widely distributed in freshwater environments, such as streams and lakes, and are an important component in the aquatic ecology of unpolluted streams. They are highly sensitive to low concentrations of environmental toxins and possess a sensitive neurological system with a true brain, which allows for complex social behaviour [17]. Moreover, planarians have a high regeneration capacity. When a planarian is cut into several parts, whether cut transversally, longitudinally, or into tiny fragments, each part can regenerate into a complete organism [18]. Therefore, planarians are a kind of suitable organism for testing teratogenic effects. Planarians have been used as indicators of water quality and toxic effects of various substances [19]. In addition, planarians are inexpensive and easily cultivated in laboratory conditions. These properties of planarians make them attractive for environmental monitoring. In this study, we used Dugesia japonica planarians (which belong to the phylum Platyhelminthes, class Turbellaria, order Tricladida, family Dugesiidae) as an animal assay to evaluate the toxicological effects of PFOAs on behavioral activity, survival, regeneration, antioxidant enzyme activities, and cell apoptosis of the D. japonica freshwater planarians.

\section{Experimental Procedures}

\section{Animals and Chemicals}

Freshwater planarians (D. japonica) were collected from a non-polluted fountain in Quanhetou, Boshan, China. Planarians were cultivated in tanks with aerated tap water at $20^{\circ} \mathrm{C}$. The water was changed every day during acclimatization. The planarians were fed twice a week with pig liver until use. Perfluorooctanoic acid (PFOA, purity=96\%) was purchased from Sigma-Aldrich (St. Louis, USA). The stock solution $(500 \mathrm{mg} / \mathrm{L})$ was prepared by dissolving it in dimethyl sulfoxide (DMSO) and stored at $4^{\circ} \mathrm{C}$.

\section{Acute Toxicity Test}

A control and seven concentrations of PFOA (10, 30, $35,40,45,50$, and $55 \mathrm{mg} / \mathrm{L})$ were used in triplicate. For each replicate 10 planarians (10-12 $\mathrm{mm}$ in length) were
Table 1. $\mathrm{LC}_{50}$ values from 24 to $96 \mathrm{hr}$ for Dugesia japonica exposed to different PFOA concentrations.

\begin{tabular}{|c|c|c|}
\hline $\begin{array}{c}\text { Exposure time } \\
(\mathrm{hr})\end{array}$ & $\begin{array}{c}\mathrm{LC}_{50} \\
(\mathrm{mg} / \mathrm{L})\end{array}$ & $\begin{array}{c}95 \% \text { Confidence } \\
\text { interval }\end{array}$ \\
\hline 24 & 45.17 & $35.24-55.10$ \\
\hline 48 & 42.94 & $33.75-52.14$ \\
\hline 72 & 41.09 & $33.93-48.24$ \\
\hline 96 & 39.35 & $32.38-46.32$ \\
\hline
\end{tabular}

placed in each vessel. The control and exposure planarians received DMSO $(0.005 \%$, v/v). During bioassay, the toxic solution and control water was changed every day. The planarians were exposed to the experimental conditions for a period of $96 \mathrm{hr}$. The mortality was recorded every $24 \mathrm{hr}$, and the dead animals were removed in each observation. Mean lethal concentrations $\left(\mathrm{LC}_{50}\right)$ were derived through a Probits analysis [20].

\section{Behavior Assessment}

The planarians were continuously exposed to $0,0.5,1$, 5, 10, and $15 \mathrm{mg} / \mathrm{L}$ PFOA for 1 day, 4 days, 7 days, and 10 days before behavior testing. Each treatment was conducted with a total of 30 planarians per treatment condition (10 planarians per replicate and three replicates per treatment). Planarian locomotor velocity ( $\mathrm{pLMV}$ ) was measured as previously described [21]. Individual planarians were placed with a soft paintbrush into transparent glass petri dishes (10 cm diameter) containing treatment water. The dishes were placed over paper with gridlines spaced $0.5 \mathrm{~cm}$ apart. pLMV was quantified as the number of gridlines crossed or re-crossed by planarians per minute over an 8 minute observation period. The data were collected every minute and further analyzed using SPSS 16.0 software. After the locomotion measurement, the planarians were placed back in their respective treatment vessels. During bioassay, the toxic solution and control water was changed every day. After 10 days exposure, the planarians were put into PFOA-free water recovering for three days, and pLMV was measured daily.

\section{Regeneration Assay}

The planarians were transversely cut just behind their auricles, and the tail fragments were allowed to regenerate at six different PFOA concentrations $(0,0.5,1,5,10$, and $15 \mathrm{mg} / \mathrm{L})$ at $20^{\circ} \mathrm{C}$ for 10 days. Each treatment was conducted with a total of 30 planarians per treatment condition (10 planarians per replicate and three replicates per treatment). The regeneration of the eyespots and auricles was traced by daily observation in a Nikon SMZ1500 stereomicroscope during the process of regeneration. And the number of planarians with a pair of well-formed eyespots and auricles in each sample also was recorded. 


\section{Enzyme Assays}

The planarians were homogenized in phosphate buffer ( $\mathrm{pH} 7.0)$ after 1 day, 4 days and 10 days exposure to PFOA $(0,0.5,1,5,10$, and $15 \mathrm{mg} / \mathrm{L})$, respectively, and the homogenates were centrifuged at $6000 \mathrm{r} / \mathrm{min}$ for $15 \mathrm{~min}$ in a cooling centrifuge $\left(4^{\circ} \mathrm{C}\right)$. Supernatants were collected for antioxidant enzyme analysis. Protein content was determined by the method of Bradford et al. [22] using bovine serum albumin as the standard.

Total superoxide dismutase (SOD) activity was determined using the method of Marklund and Marklund [23] based on the autoxidation of pyrogallol. One unit of enzyme activity is defined as the amount of enzyme that produced a $50 \%$ inhibition of autoxidation of pyrogallol under assay conditions in one minute. Superoxide dismutase activity was assessed spectrophotometrically at $420 \mathrm{~nm}$ and expressed as an amount of enzyme permilligram of protein.

The catalase (CAT) activity was measured by ultraviolet spectrophotometer following the method of Aebi [24] and was determined from the rate of $\mathrm{H}_{2} \mathrm{O}_{2}$ decrease in absorbance at $240 \mathrm{~nm}$.

\section{Cell Apoptosis}

Planarian cell apoptosis was identified using acridine orange (AO) staining [25]. After the planarians were exposed to $0,1,5,10,15$, and $25 \mathrm{mg} / \mathrm{L}$ PFOA for 7 days or exposed to $10 \mathrm{mg} / \mathrm{L}$ PFOA for 2 days, 7 days, and 10 days, the planarians were washed twice in phosphate-buffered saline (PBS) and then transferred to PBS solution containing $5 \mu \mathrm{g} / \mathrm{ml} \mathrm{AO}$ and stained for $1 \mathrm{hr}$ at room tem- perature in the dark. The Planarians were then washed with PBS three times for $5 \mathrm{~min}$ each. Fluorescence in each planarian was photographed with a fluorescence microscope (Nikon, Japan). Apoptotic cells appeared as obvious bright spots.

\section{Statistical Analysis}

All the data were reported as means \pm standard error (SEM) and analyzed by SPSS 16.0 software (IBM, USA). One-way ANOVA was applied to calculate statistical significance followed by a Tukey's post-hoc analysis and compared each exposure group with the control group. P-values lower than 0.05 were considered as significant for all statistical analysis.

\section{Results}

\section{Effect of PFOA on SOD and CAT Activity}

$\mathrm{LC}_{50}$ values of PFOA for planarians are summarized in Table 1 . The results show that the mortality is directly proportional to the PFOA concentration. The 24, 48, 72, and 96 $\mathrm{hr} \mathrm{LC}_{50}$ values of PFOA for planarians in this study are $45.17,42.94,41.09$, and $39.35 \mathrm{mg} / \mathrm{L}$, respectively.

\section{Effect of PFOA on Planarian Locomotor Velocity}

Changes in planarian locomotor velocity (pLMV) in response to exposure to PFOA are shown in Fig. 1. The data are plotted as the cumulative means of each group over the 8-min observation period. The pLMV of Planarians exposed a)

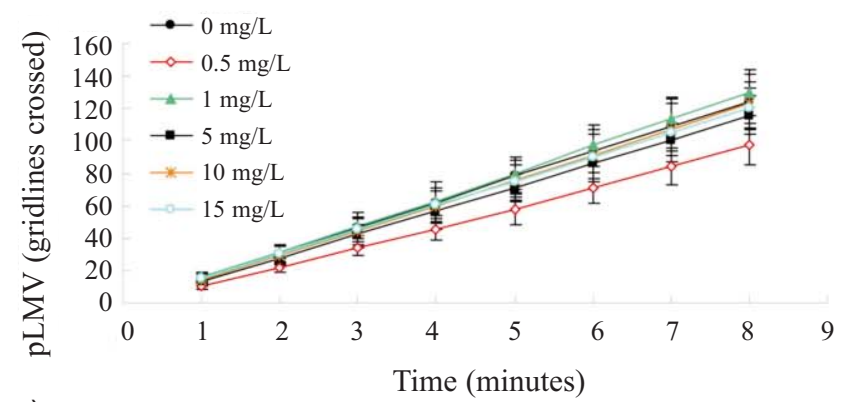

c)

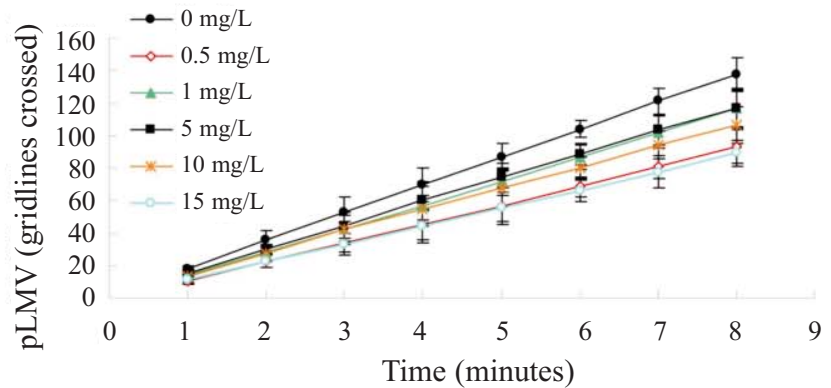

b)

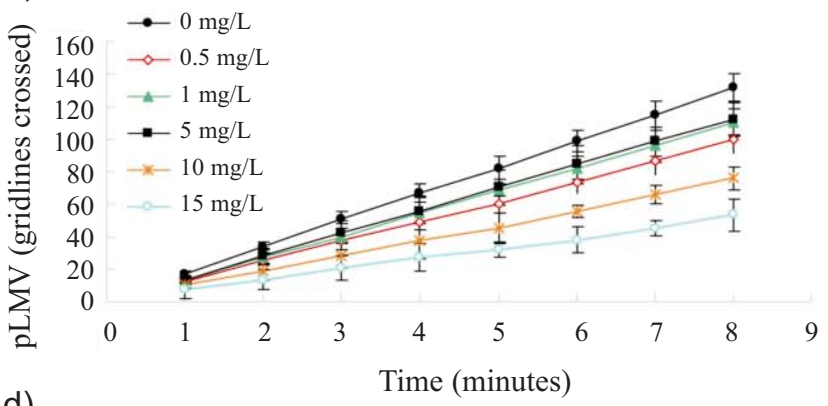

d)

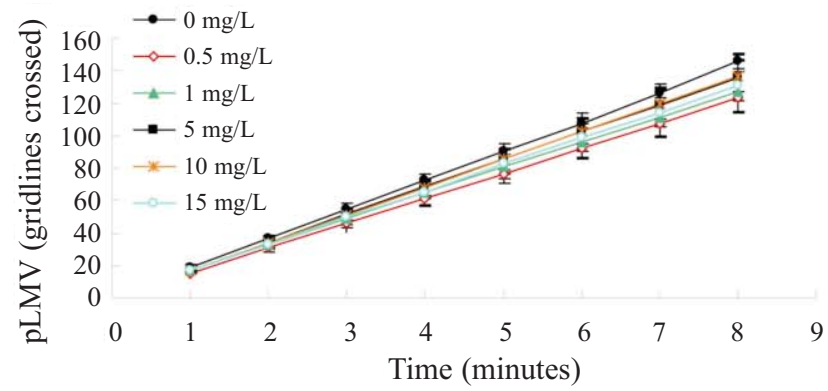

Fig. 1. The behavioral activity of the planarians exposed in solutions with various PFOA concentrations for 1 day (a), 10 days (b), and recovery in PFOS-less water for 1 day (c), 3 days (d). pLMV was quantified as the number of gridlines crossed or re-crossed per minute over an 8-min. interval and expressed as the mean $\pm \mathrm{SD}$ of the cumulative number of gridlines crossed by each planarian per min. 
to increasing PFOA concentrations for only 1 day is not significantly different $(\mathrm{P}>0.05)$ from the controls (Fig. 1a). Planarians exposed continuously to 10 and $15 \mathrm{mg} / \mathrm{L}$ PFOA for 10 days is found to have lower pLMV than the controls (Fig. 1b). Recovering assay shows that planarians pre-treated with $15 \mathrm{mg} / \mathrm{L}$ PFOA still have significantly lower pLMV $(\mathrm{P}<0.05)$ than the controls (Fig. 1c) after $24 \mathrm{hr}$ recovery. After $72 \mathrm{hr}$, all planarians completely recover their motility and have no different pLMV (Fig. 1d).

\section{Effect of PFOA on the Appearance of Eyespots and Auricles in Regenerating Planarians}

Regeneration assay indicates that the appearance of eyespots in regenerating animals is affected significantly after 5-day exposure to 5 and $15 \mathrm{mg} / \mathrm{L}$ PFOA in comparison with the controls $(\mathrm{P}<0.05)$ (Fig. 3a). After 6 days exposure, the appearance of eyespots in regenerating animals exposed to all of the tested concentrations has no significant difference in comparison with the controls $(\mathrm{P}>0.05)$ (Fig. 3a). However, the appearance of auricles in regenerating animals is inhibited significantly by exposure in all testing concentrations during the regeneration process in comparison with the controls $(\mathrm{P}<0.05)$ (Fig. $2 b)$.

\section{Effect of PFOA on SOD and CAT Activity}

Results show that PFOA treatment alters planarian antioxidant enzyme activity compared with the controls (Fig. 3). The main perturbation of SOD is induced after 1d

a)

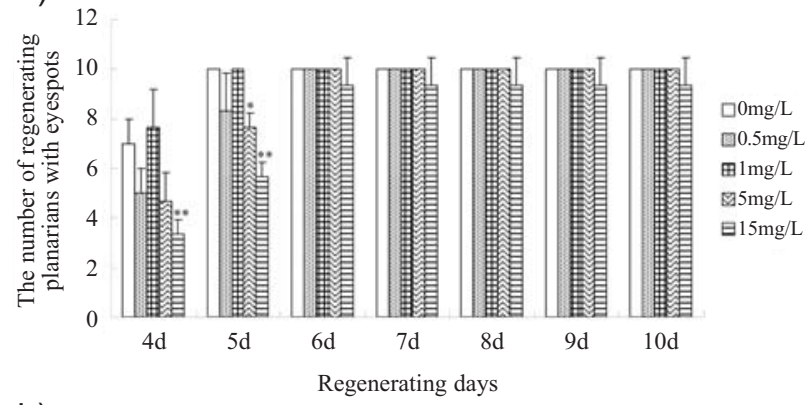

b) 12

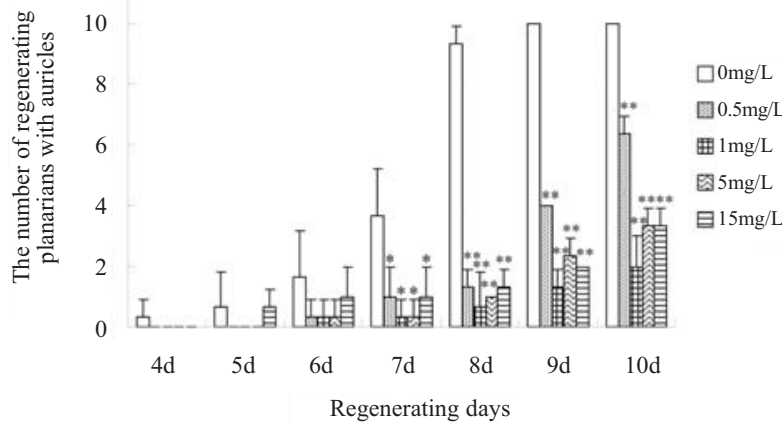

Fig. 2. The regeneration performance of the planarians exposed in solutions with various PFOA concentrations during regeneration process, including eyespots (a) and auricles (b). Mean values $\pm \mathrm{SD}$ are shown. ${ }^{*} \mathrm{P}<0.05,{ }^{*} * \mathrm{P}<0.01$, compared to controls (one-way ANOVA followed by Tukey's post-hoc test). exposure to PFOA, with a global trend to up-regulation (except for at the $0.5 \mathrm{mg} / \mathrm{L}$ ) (Fig. 3a). For SOD, a global return to the control levels is observed afterward, except for the significant down-regulation at $0.5 \mathrm{mg} / \mathrm{L}$ (4 days).

Compared to SOD, the antioxidant enzymes CAT responds in a different way in D. japonica (Fig. 3b). The main perturbation of CAT is induced after 10 days exposure to PFOA with a global trend to up-regulation (highly significant up-regulation at 5,10 , and $15 \mathrm{mg} / \mathrm{L}$ ). A weak but visible increase in CAT activity occurs after four days exposure to $1 \mathrm{mg} / \mathrm{L}$ PFOA.

\section{Apoptosis Induced by Various Concentrations of PFOA on Planarians}

Apoptosis assays have been performed to determine if the exposure to PFOA affects apoptosis in tissues. As observed, there are only a few apoptotic cells in the control planarians or the $1 \mathrm{mg} / \mathrm{L}$ PFOA group, but a strong labeling of apoptotic cells is found in the head and parenchyma region of planarians treated with $5,10,15$, or $25 \mathrm{mg} / \mathrm{L}$ PFOA for 7 days (Fig. 4)

\section{Discussion}

Acute toxicity of PFOA to planarians was carried out in the present study. The results show that planarians respond strongly to PFOA toxicity in the first $24 \mathrm{hrs}$, but no obvious toxicity increment from 48 to $96 \mathrm{hrs}$. The $24,48,72$, and 96h $\mathrm{LC}_{50}$ values of PFOA for planarians in our study are $45.17,42.94,41.09$, and $39.35 \mathrm{mg} / \mathrm{L}$, which is less than those of the previous studies [26, 27]. Li [26] reported that
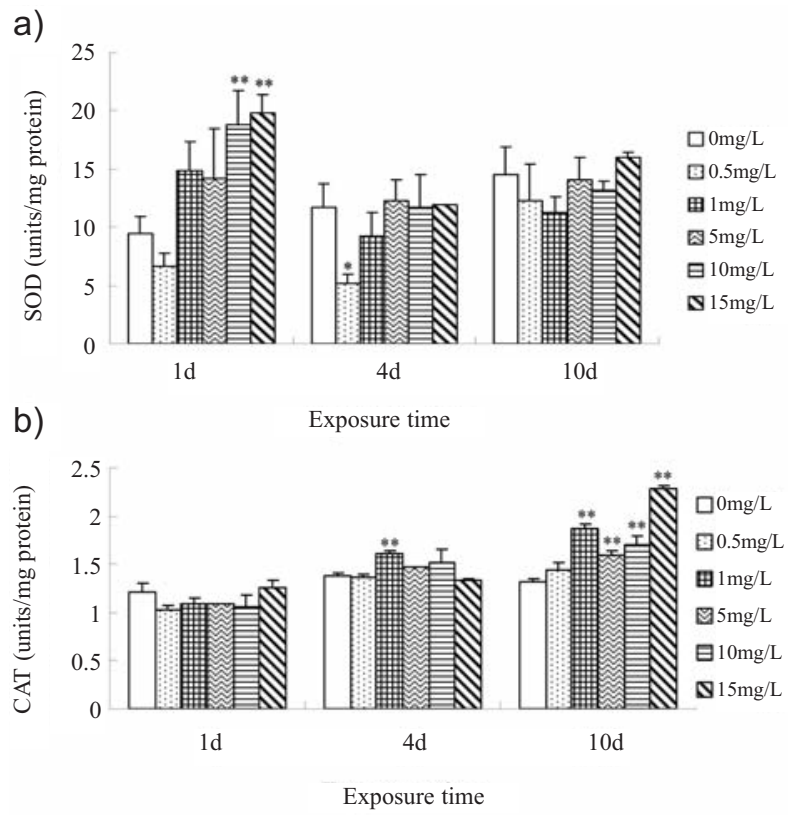

Fig. 3. The antioxidant enzyme activities including SOD (a) and CAT (b) in planarians exposed in solutions with various PFOA concentrations for 1 day, 4 days, and 10 days. Mean values \pm SD are shown. $* \mathrm{P}<0.05$, $* * \mathrm{P}<0.01$, compared to controls (one-way ANOVA followed by Tukey's post-hoc test). 
the $24,48,72$, and $96 \mathrm{hC}_{50}$ values of PFOA for planarians were $548,536,519$, and $458 \mathrm{mg} / \mathrm{L}$. $\mathrm{Li}$ [26] reported that the 24, 48, 72, and 96h $\mathrm{LC}_{50}$ values of PFOS for planarians were $352,345,343$, and $337 \mathrm{mg} / \mathrm{L}$. In our previous study, the $24,48,72$, and $96 \mathrm{~h} \mathrm{LC}_{50}$ value of PFOS for planarians are $40.72,38.45,32.92$, and $29.46 \mathrm{mg} / \mathrm{L}$, indicating that PFOA is less toxic than PFOS to planarians, which is in agreement with those in previous studies [26-28].

Behaviour is normally altered before death, growth, and reproduction. Many studies have shown that behaviour is a more sensitive biomarker than mortality [29]. Therefore, the behavioral effects of PFOA in planarians have been also examined in the present study. The results show that exposure to PFOA has significant effects on the behavior of the planarians. Time and concentration-response patterns of PFOA toxicity are observed for planarians. We have not seen a differential swimming response between PFOAtreated and control planarians after one day of exposure. PFOA elicits a lower pLMV after seven or 10 days of exposure to each concentration in comparison with the control. Further studies are needed to understand the mechanisms at the physiological or neurochemical levels that underlie behavioral responses of PFOA on planarians.

Planarians can regenerate their whole body from small pieces after being cut or injured [30]. In most cases, regeneration can be complete within a week to 10 days. Our results show that the appearance of auricles in regenerating animals is more easily affected by PFOA exposure in comparison to the appearance of eyespot. Similar results have been reported in our previous study of effects of the anionic surfactants sodium dodecyl sulphate on regeneration of planarian Dugesia japonica [31]. The results of all of these studies suggest that the reduced appearance of auricles may be a general response of planarians exposed to toxicants.

Several studies have demonstrated that environmental pollution induces the production of ROS, which may be scavenged by the antioxidant defense system $[32,33]$. The activity of enzymes such as SOD and CAT prevent adverse effects of oxidative stress in cells. SOD catalyzes the dismutation of the superoxide anion radical to $\mathrm{O}_{2}$ and $\mathrm{H}_{2} \mathrm{O}_{2}$. and CAT acts as scavengers of $\mathrm{H}_{2} \mathrm{O}_{2}$ [27]. Previous studies indicate that PFCs have the potential to induce oxidative stress via interference with the antioxidant defense system and induce cell apoptosis in different experimental models $[10,34]$. The increase of SOD activities in the one-day PFOA-exposed planarians and the increase CAT activities in the 10-day PFOA-exposed planarians reflects the need for planarians to mediate $\mathrm{O}_{2}^{--}$and $\mathrm{H}_{2} \mathrm{O}_{2}$ overproduction due to the PFOA, whatever its concentration. The behavior might be related to the associated sequential changes in oxidative stress response by planarians: first, SOD converts $\mathrm{O}_{2}^{--}$to $\mathrm{H}_{2} \mathrm{O}_{2}$ and then CAT converts $\mathrm{H}_{2} \mathrm{O}_{2}$ to $\mathrm{H}_{2} \mathrm{O}$ [35]. However, it is unclear whether the observed increase of SOD and CAT results from a chemically induced increase in mRNA stability or from an increase in protein translation by PFOA.

Stress-induced apoptosis is thought to contribute to abnormal development during regeneration. To our knowledge, this is the first study to evaluate the apoptosis induced by the PFOA exposure in planarians. AO staining reveals that apoptotic cells mainly occur in the head and parenchyma areas in our study, which suggests that the developing head may be an important potential target for PFOA in planarians. Enhanced cell apoptosis in the head may partly explain the observed reduced appearance of auricles in the present study. Increasing PFOA concentration increases significantly apoptosis in the brain, eye, and parenchyma region. Austin et al. [36] reported that PFCs may accumulate in brain in adult rats. Huang et al. [25] also found significantly increased apoptosis in the brain and eye regions in zebra fish embryos. Cell apoptosis may also partially contribute to behavioral disruption observed in the present study as the brain is the most important region for planarian behavior response.

Although the exposure concentrations tested in our study were greater than those measured in the actual concentrations that are found in most aquatic ecosystems, PFOA levels can range from 1.3 to $297.5 \mathrm{ng} / \mathrm{L}$ in some surface water, and total PFC concentrations can range up to 17 $\mathrm{mg} / \mathrm{L}$ in downstream of spills $[4,37]$. Moreover, PFCs can
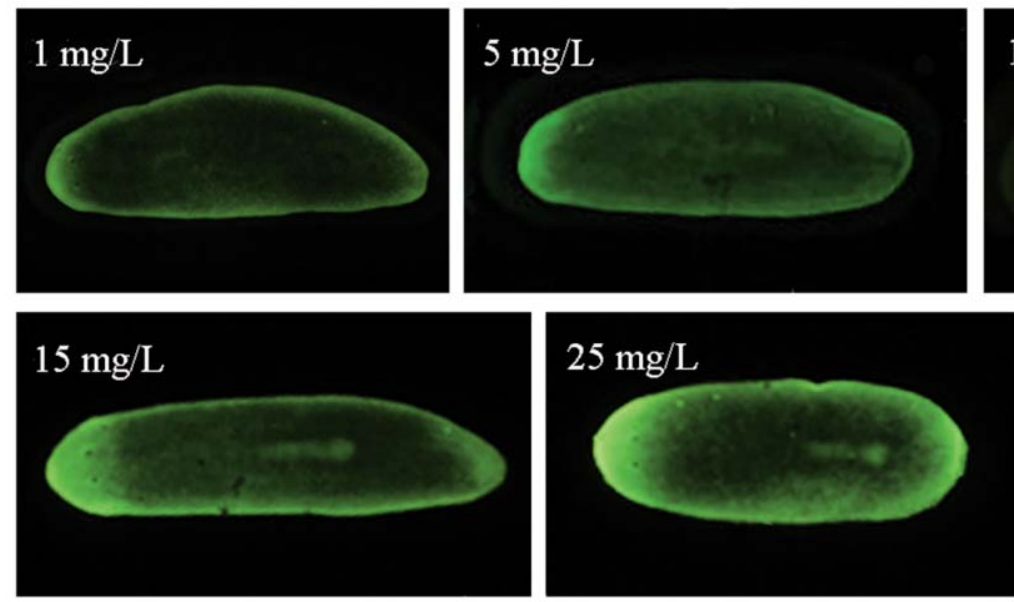

Fig. 4. Detection of apoptosis in planarians after exposure to PFOA at 1-25 mg/L for seven days using acridine orange (AO) assay.

Scale bars represent $100 \mu \mathrm{m}$

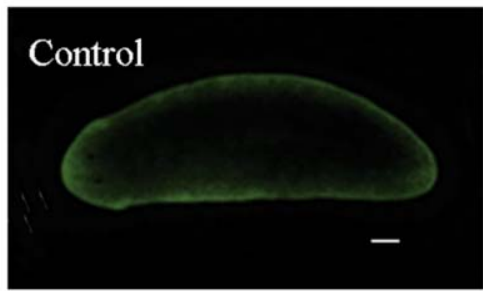


persist and bioaccumulate following release into the aquatic environment [37]. Relatively higher concentrations of toxicants are often used in laboratory exposures to elicit clearly distinguishable effects that allow possible toxic mechanisms to be determined [38]. In future study, we will study the chronic effects of PFOA using the environmentally realistic concentrations.

\section{Conclusions}

In summary, our study shows that mortality is directly proportional to PFOA concentration, and planarian locomotor velocity is reduced significantly with increasing both exposure time and PFOA concentration. The appearance of auricles in regenerating animals is easier to be affected by PFOA exposure in comparison with the appearance of eyespots. The SOD activities are found to be increased in the one day PFOA-exposed planarians while the CAT activities need 10 days of PFOA-exposure. Increasing PFOA exposure time or concentration increase significantly apoptosis in the brain, eye, and parenchyma region. The results suggest that PFOA has much higher toxity in inducing oxidative stress, cell apoptosis, and development toxicity in planarians. In the future we will study the chronic effects of PFOA using environmentally realistic concentrations.

\section{Acknowledgements}

We thank the members of our laboratory for suggestions and encouragement. Research was supported by the National Nature Science Foundation of China (grant No. 41201518, 31100377), a project of the Shandong Province Higher Educational Science and Technology Program (grant No. J11LC09), and a project for the Young Teacher Development Support Program of Shandong University of Technology.

\section{References}

1. GIESY J.P., KANNAN K. Global distribution of perfluorooctane sulfonate in wildlife. Environ. Sci. Technol. 35, (7), 1339, 2001.

2. BUTENHOFF J.L., GAYLOR D.W., MOORE J.A., OLSEN G.W., RODRICKS J., MANDEL J.H., ZOBEL L.R. Characterization of risk for general population exposure to perfluorooctanoate. Regul Toxicol Pharmacol. 39, (3), 363, 2004.

3. DIETZ R., BOSSI R., RIGE'T F.F., SONNE C., BORN E.W. Increasing perfluoroalkyl contaminants in east Greenland polar bears (Ursus maritimus): A new toxic threat to the Arctic bears. Environ Sci Technol. 42, (7), 2701, 2008.

4. JIN Y.H., LIU W., SATO I., NAKAYAMA S.F., SASAKI K., SAITO N., TSUDA S. PFOS and PFOA in environmental and tap water in China. Chemosphere. 77, (5), 605, 2009.

5. LOOS R., LOCORO G., HUBER T., WOLLGAST J.,
CHRISTOPH,E.H., DE JAGER A., MANFRED GAWLIK B., HANKE G., UMLAUF G., ZALDIVAR J.M. Analysis of perfluorooctanoate (PFOA) and other perfluorinated compounds (PFCs) in the River Po watershed in N-Italy. Chemosphere. 71, (2), 306, 2008.

6. CALAFAT A.M., KUKLENYIK Z., REIDY J.A., CAUDILL S.P., TULLY J.S., NEEDHAM, L.L. Serum concentrations of 11 polyfluoroalkyl compounds in the u.s. population: data from the national health and nutrition examination survey (NHANES). Environ. Sci. Technol. 41, (7), 2237, 2007.

7. GURUGE K., YEUNG L.W.Y., YAMANAKA N., MIYAZAKI S., LAM P.K.S., GIESY J.P., JONES P.D., YAMASHITA N. Gene expression profiles in rat liver treated with perfluorooctanoic acid (PFOA). Toxicol. Sci. 89, (1), 93, 2006.

8. KENNEDY G.L.Jr., BUTENHOFF J.L., OLSEN G.W., O'CONNOR J.C., SEACAT A.M., PERKINS R.G., BIEGEL L.B., MURPHY S.R., FARRAR D.G. The toxicology of perfluorooctanoate. Crit Rev Toxicol. 34, (4), 351, 2004.

9. ANKLEY G.T., KUEHL D.W., KAHL M.D., JENSEN K.M., LINNUM A., LEINO R.L., VILLENEUVET D.A. Reproductive and developmental toxicity and bioconcentration of perfluorooctanesulfonate in a partial life-cycle test with the fathead minnow (Pimephales promelas). Environ. Toxicol. Chem. 24, (9), 2316, 2005.

10. LIU C., YU K., SHI X., WANG J., LAM P.K., WU R.S., ZHOU B. Induction of oxidative stress and apoptosis by PFOS and PFOA in primary cultured hepatocytes of freshwater tilapia (Oreochromis niloticus). Aquat Toxicol. 82, (2), 135, 2007.

11. LUEBKER D.J, HANSEN K.J., BASS N.M., BUTENHOFF J.L. Interactions of fluorochemicals with rat liver fatty acid-binding protein. Toxicology. 176, (3), 175, 2002.

12. BIEGEL L.B., HURTT M.E., FRAME S.R., O'CONNOR J.C., COOK J.C. Mechanisms of extrahepatic tumor induction by peroxisome proliferators in male $\mathrm{CD}$ rats. Toxicol. Sci. 60, (1), 44, 2001.

13. COOK J.C., MURRAY S.M., FRAME S.R., HURTT M.E. Induction of Leydig cell adenomas by ammonium perfluorooctanoate: A possible endocrine-related mechanism. Toxicol Appl Pharmacol. 113, (2), 209, 1992.

14. SEACAT A.M., THOMFORD P.J., HANSEN K.J., CLEMEN L.A., ELDRIDGE S.R., ELCOMBE C.R., BUTENHOFF J.L. Sub-chronic dietary toxicity of potassium perfluorooctanesulfonate in rats. Toxicology. 183, (1-3), 117, 2003.

15. WALTERS M.W., BJORK J.A., WALLACE K.B. Perfluorooctanoic acid stimulated mitochondrial biogenesis and gene transcription in rats. Toxicology. 264, (1-2), 10, 2009.

16. WANG F., SHIH K. Adsorption of perfluorooctanesulfonate (PFOS) and perfluorooctanoate (PFOA) on alumina: influence of solution $\mathrm{pH}$ and cations. Water Res. 45, (9), 2925, 2011.

17. NANO G.M., BINELLO A., BIANCO M.A., UGAZIO G., BURDINO S. In vitro tests to evaluate potential biological activity in natural substances. Fitoterapia. 73, (2), 140, 2002.

18. SÁNCHEZ ALVARADO A. Regeneration and the need for simpler model organisms. Philos Trans R Soc Lond B Biol Sci. 359, (1445), 759, 2004.

19. KOVAČEVIĆ G., GREGOROVIĆ G., KALAFATIĆ M., JAKLINOVIĆ I. The Effect of Aluminium on the Planarian Polycelis felina (Daly.) Water Air Soil Pollut. 196, 333, 2009. 
20. ZHOU Y.X., ZHANG Z.S. Methods of aquatic toxicology analysis. Agriculture Publisher of China, Beijing. pp. 114$122,1989$.

21. RAFFA R.B., HOLLAND L.J., SCHULINGKAMP R.J. Quantitative assessment of dopamine D2 antagonist activity using invertebrate (Planaria) locomotion as a functional endpoint. J Pharmacol Toxicol Methods. 45, (3), 223, 2001

22. BRADFORD M.M. A rapid and sensitive method for the quantitation of microgram quantities of protein utilizing the principle of proteindye binding. Anal Biochem. 72, 248, 1976.

23. MARKLUND S., MARKLUND G. Involvement of superoxide anion radical in the autoxidation of pyrogallol and a convenient assay for superoxide dismutase. Eur. J. Biochem. 47, (3), 469, 1974.

24. AEBI H. Catalase in vitro, Method Enzymol. 105, 121, 1984.

25. HUANG H., HUANG C., WANG L., YE X., BAI C., SIMONICH M.T., TANGUAY R.L., DONG Q. Toxicity, uptake kinetics and behavior assessment in zebrafish embryos following exposure to perfluorooctanesulphonicacid (PFOS). Aquat Toxicol. 98, (2), 139, 2010.

26. LI M.H. Effects of nonionic and ionic surfactants on survival, oxidative stress, and cholinesterase activity of planarian. Chemosphere. 70, (10), 1796, 2008.

27. LI M.H. Toxicity of perfluorooctane sulfonate and perfluorooctanoic acid to plants and aquatic invertebrates. Environ. Toxicol. 24, (1), 95, 2009.

28. ZHENG X.M., LIU H.L., SHI W., WEI S., GIESY J.P., YU H.X. Effects of perfluorinated compounds on development of zebrafish embryos. Environ Sci Pollut Res Int.19, (7), 2498, 2011.

29. ALONSO A., CAMARGO J.A. The freshwater planarian Polycelis felina as a sensitive species to assess the long-term toxicity of ammonia. Chemosphere. 84, (5), 533, 2011.

30. NEWMARK P. A., SANCHEZ ALVARADO A. Not your father's planarian: A classic model enters the era of functional genomics. Nat Rev Genet. 3, (3), 210, 2002.
31. YUAN Z.Q., ZHENG M.Y., ZHANG J.Y., ZHAO S.Z., GUO L., ZHAO B.S. Effects of Anionic Surfactants Sodium Dodecyl Sulphate on Regeneration and Antioxidant Enzymes Response of Planarian Dugesia japonica. Fresen Environ Bull. 22, (1), 157, 2013.

32. FATIMA M., MANDIKI S.N.M., DOUXFILS J., SILVESTRE F., COPPE P., KESTEMONT P. Combined effects of herbicideson biomarkers reflecting immune-endocrine interactions in gold fish immune and antioxidant effects. Aquat Toxicol. 81, (2), 159, 2007.

33. JIN Y., PAN X., CAO L., MA B., FU Z. Embryonic exposure to cis-bifenthrin enantioselectively induces the transcription of genes related to oxidative stress, apoptosis and immunotoxicity in zebrafish (Danio rerio). Fish Shellfish Immunol. 34, (2), 717, 2013.

34. SHI X., DU Y., LAM P.K., WU R.S., ZHOU B. Developmental toxicity and alteration of gene expression in zebrafish embryos exposed to PFOS. Toxicol. Appl. Pharmacol. 230, (1), 23, 2008

35. XIONG W., SUN Y., ZOU M., MUHAMMAD R.U. Molecular cloning, characterization of CAT, and eco-toxicological effects of dietary zinc oxide on antioxidant enzymes in Eisenia fetida. Environ Sci. Pollut. Res. Int. 20, (3), 1746, 2013.

36. AUSTIN M.E., KASTURI B.S., BARBER M., KANNAN K., MOHANKUMAR P.S., MOHANKUMAR S.M. Neuroendocrine effects of perfluorooctane sulfonate in rats. Environ Health Perspec. 111, (12), 1485, 2003.

37. MOODY C.A., MARTIN J.W., KWAN W.C., MUIR D.C.G., MABURY S.A. Monitoring perfluorinated surfactants in biota and surface water samples following an accidental release of fire-fighting foam into Etobicoke Creek. Environ Sci Technol. 36, 545, 2002.

38. LEMA S.C., SCHULTZ I.R., SCHOLZ N.L., INCARDONA J.P., SWANSON P. Neural defects and cardiac arrhythmia in fish larvae following embryonic exposure to 2,2',4,4'-tetrabromodiphenyl ether (PBDE 47). Aquat. Toxicol. 82, 296, 2007. 
